\title{
A Cephalometric Study of Relationship of Anterior Teeth to Incisive Papilla, Mucolabial Reflections and A-Pogonion Line in Dentulous Subjects and In Complete Denture Wearers
}

\author{
Venus Sidana, Neeta Pasricha, Sonia Nanda* and Navneet Mann
}

Department of Prosthodontics and Crown and Bridge, National Dental College, Derabassi, Punjab, India

\begin{abstract}
Facial appearance influences the social acceptance and psychological well-being of an individual. Prosthodontic treatment restores the lost support. Regardless of judgment and technical ability the dentist can place the artificial teeth more correctly if some natural stable landmarks are available to guide. In this study, lateral cephalograms were used to determine the relation of anterior teeth to incisive papilla, mucolabial reflections and A-Pogonion line in dentulous subjects and in complete denture wearers.

The results of this study indicate that within dentulous subjects there is no significant difference in the horizontal or vertical relationship of anterior teeth with various landmarks such as incisive papilla, mucolabial reflections and A-Pog line, irrespective of age group. In complete denture wearer, the dentures which were constructed to esthetic and phonetic sense of dentist, there is not much variation in labiolingual position of anterior teeth, as compared to the natural teeth; however, there was slight increase in the vertical measurement from the denture borders to the tips of maxillary and mandibular incisors.
\end{abstract}

Keywords: Incisive Papilla; Mucolabial reflections; A-Pogonion line.

\section{Introduction}

Human beings have been aware of beauty and facial esthetics throughout recorded history and even earlier as evidenced by archeological artifacts. The study of facial esthetics has been primarily the domain of painters, sculptors and philosophers.

In thirteenth century, Thomas Aquinas stated a fundamental truth of esthetics" The senses delight in things duly proportioned" [1]. Dentists have contributed to this ongoing effort with their study of human face and profile. It is a complex and challenging problem to give edentulous patients the teeth, which compares favorably with natural teeth.

The anterior teeth influence the contour of lower third of the face as well as tonicity of muscles of the expression. Correct or ideal position of teeth for best facial contour has long been of concern to dentist. It is impossible to anticipate the total success in denture construction for all patients, but esthetically we have narrowed the gap between trial and error methods and have predetermined success by the development of various techniques.

Cephalometrics application in prosthodontics is well known today. Several studies have been conducted to determine vertical height, occlusal plane etc. using this as an aid [2-5]. However, not much thought has been focused in which cephalometrics is used to study the anatomical landmarks which would help in arranging the artificial teeth. Hence, a cephalometric study was planned in which surface anatomy of oral tissues can be utilized as guidelines in the placement of anterior teeth on denture base.

In this study, lateral cephalogram was used to determine the relation of anterior teeth to incisive papilla, mucolabial reflections and A-Pogonion line in dentulous subjects and in complete denture wearers (Figure 1).

\section{Aims and Objectives}

1. To find out the horizontal distance between labial surface of maxillary incisor and distal margin of incisive papilla in dentulous subjects and in complete denture wearers.

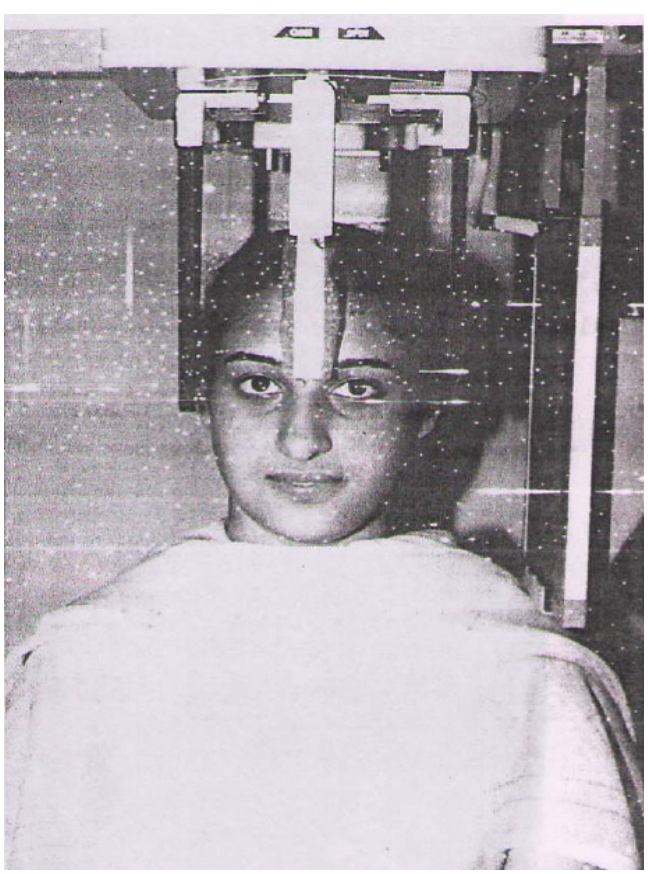

Figure 1: Subject positioned for lateral cephalogram.

*Corresponding author: Dr. Sonia Nanda, Department of Prosthodontics and Crown and Bridge, National Dental College, Derabassi, Punjab, India. Tel: 8607865955; E-mail: drsonia84@gmail.com

Received: June 09, 2017; Accepted: July 20, 2017; Published: July 25, 2017

Citation: Sidana V, Pasricha N, Nanda S, Mann N (2017) A Cephalometric Study of Relationship of Anterior Teeth to Incisive Papilla, Mucolabial Reflections and A-Pogonion Line in Dentulous Subjects and In Complete Denture Wearers. Oral health case Rep 3: 137. doi:10.4172/2471-8726.1000137

Copyright: (C) 2017 Sidana V, et al. This is an open-access article distributed under the terms of the Creative Commons Attribution License, which permits unrestricted use, distribution, and reproduction in any medium, provided the original author and source are credited. 
Citation: Sidana V, Pasricha N, Nanda S, Mann N (2017) A Cephalometric Study of Relationship of Anterior Teeth to Incisive Papilla, Mucolabial Reflections and A-Pogonion Line in Dentulous Subjects and In Complete Denture Wearers. Oral health case Rep 3: 137. doi:10.4172/24718726.1000137

Page 2 of 6

2. To find out the vertical distance between mucolabial reflections and maxillary and mandibular incisors in dentulous subjects.

3. To find out the vertical distance between denture borders and maxillary and mandibular incisors in complete denture wearers.

4. To find out the horizontal distance between mucolabial reflections and labial surfaces of maxillary and mandibular incisors in dentulous subjects.

5. To find out the horizontal distance between denture borders and labial surfaces of maxillary and mandibular incisors in complete denture wearers.

6. To find out the horizontal distance between A-Pogonion line and maxillary and mandibular incisors in both dentulous subjects and in complete denture wearers.

\section{Materials and Methods}

The study involved dentulous subjects and complete denture wearers.

\section{Dentulous subjects}

Depending upon the age, the dentulous individuals were divided into two groups; each group consisting of twenty individuals.

Group-1 (20 years to 40 years of age)

Group-2 (40 years to 60 years of age)

The dentulous subjects were selected based on following criteria.

1. Individuals with full complement of natural teeth (third molar is not taken into consideration).

2. Individuals with class-I molar relationship.

3. Individuals with normal facial profile.

4. Individuals with single labial frenum with normal attachment.

5. Individuals without the history of previous orthodontic treatment.

6. Individuals without the history of trauma and fracture of jaws

\section{Complete denture wearers}

Group-3 consisted of twenty complete denture wearers individuals between age of 40 years to 60 years. Duration of denture wearing was within six months.

\section{Materials used in the study}

1. Cephalostat

2. Radiographic film $8 " \times 10 "$

3. Frosted acetate 0.003 " thickness tracing papers

4. Paper clips

5. Lead pencil ( $0.5 \mathrm{~mm}$ micro tip pencil)

6. Glass scale

7. X-ray view box

8. Radio-opaque paste/lead foil

\section{Lateral cephalogram in dentulous subjects}

In dentulous subjects, lateral cephalogram was taken with standard technique. The mid sagittal plane of the patient to the target distance was 5 feet and the film to mid sagittal plane was $18 \mathrm{~cm}$ (Figure 2).

Radio-opaque paste was applied in the oral cavity at the following location

1. At the height of the mucolabial reflection of the upper lip and left of labial frenum.

2. At the depth of the mucolabial reflection of the lower lip and left of labial frenum.

3. At distal point of the incisive papilla.

The subjects were instructed to close into centric occlusion and the lateral cephaogram was made.

\section{Lateral cephalogram in complete denture wearers}

In complete denture wearers, a thin lead foil was adapted on the labial borders of the upper and lower dentures and also on the maxillary and mandibular central incisors to make them radio-opaque. Lateral cephalometric radiograph was taken in same manner as for the dentulous subjects (Figure 3).

\section{Cephalometric landmarks and tracing}

The cephalometric radiographs are taken and tracing were made on frosted acetate paper with the lead pencil. Following landmarks were located and marked (Figure 4).

Point-A: The most posterior midline points in concavity between anterior nasal spine and most inferior point on alveolar bone overlying the maxillary incisors.

Pogonion-The most anterior point on bony chin.

A straight line was drawn joining Point-A and Pogonion (A-Pog line). Further a line perpendicular to A-Pog line was drawn to pass through the image of tip of maxillary incisor in order to serve as

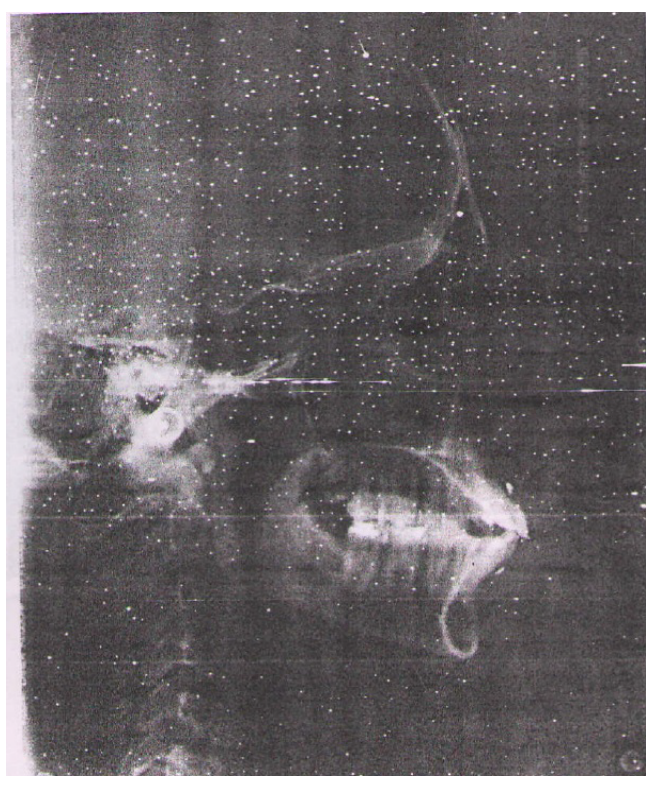

Figure 2: lateral cephalogram of the dentulous subject. 
Citation: Sidana V, Pasricha N, Nanda S, Mann N (2017) A Cephalometric Study of Relationship of Anterior Teeth to Incisive Papilla, Mucolabial Reflections and A-Pogonion Line in Dentulous Subjects and In Complete Denture Wearers. Oral health case Rep 3: 137. doi:10.4172/24718726.1000137

Page 3 of 6

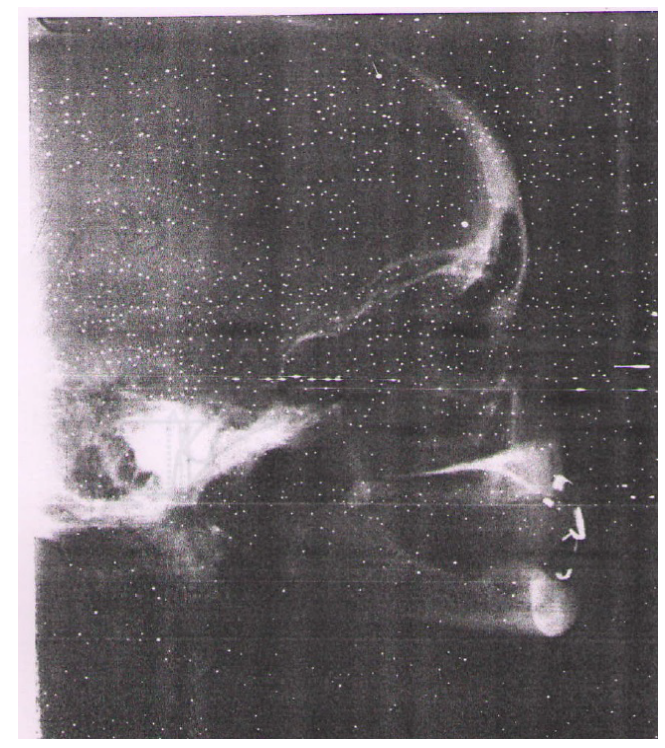

Figure 3: Lateral cephalogram of the complete denture wearer.

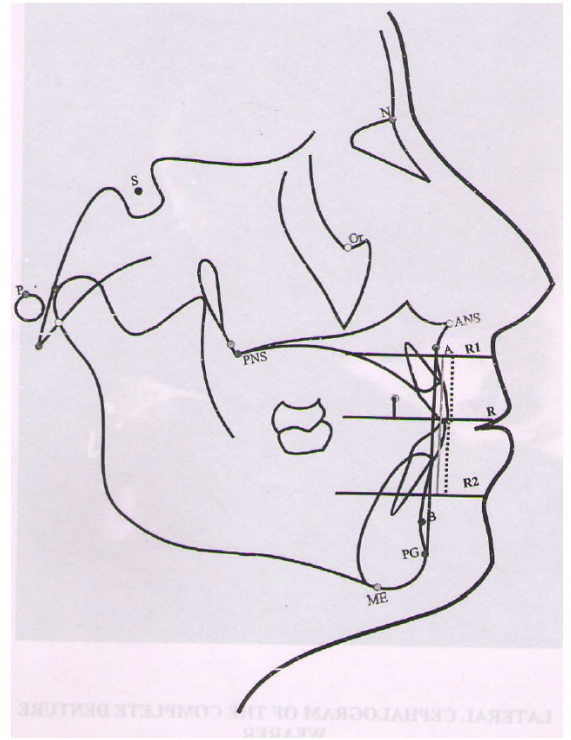

Figure 4: Cephalometric land marks and planes used in this study.

horizontal reference line $(\mathrm{R})$. Two parallel lines were drawn to reference line one from the height of maxillary mucolabial reflection $(\mathrm{Rl})$, other from the depth of mandibular mucolabial reflection (R2).

Perpendicular lines were drawn to the reference line $(\mathrm{R})$ from:

1. Height of mucolabial reflection of the upper lip (Rl).

2. Depth of mucolabial reflection of the lower lip (R2).

3. Labial surface (maximum contour of incisor teeth) of both maxillary and mandibular incisors.

Following measurement were made on tracings.

1. Horizontal distance from incisive papilla to labial surface of maxillary incisors in dentulous subjects and in complete denture wearers.
2. Vertical distance from height and depth of mucolabial reflection of upper and lower lip to the tips of maxillary and mandibular incisors in dentulous subjects.

3. Vertical distance from the borders of upper and lower dentures to maxillary and mandibular incisors in complete denture wearers.

4. Horizontal distances from height and depth of mucolabial reflection of upper and lower lip to labial surfaces of maxillary and mandibular incisors in dentulous subjects.

5. Horizontal distances from the borders of upper and lower dentures to the labial surfaces of maxillary and mandibular incisors.

6. Horizontal distances from A-Pog line to maxillary and mandibular incisors in dentulous subjects and in complete denture wearers.

\section{Results}

In this study, an attempt was made to determine following variables

Variable-1: The horizontal distance between distal margin of incisive papilla and labial surface of maxillary central incisors in dentulous subjects and in complete denture wearers (Table 1).

Variable-2: The vertical distance between the mucolabial reflection and maxillary central incisors in dentulous subjects and vertical distance between denture border and maxillary central incisors in complete denture wearers (Table 2).

Variable-3: The vertical distance between the mucolabial reflection and mandibular central incisors in dentulous subjects and vertical distance between denture border and mandibular central incisors in complete denture wearers (Table 3 ).

Variable-4: The horizontal distance between the mucolabial reflection and labial surface of maxillary central incisors and the horizontal distance between denture border and labial surface of maxillary central incisors in complete denture wearers (Table 4).

Variable-5: The horizontal distance between the mucolabial reflection and the labial surface of mandibular central incisors. The horizontal distance between denture border and labial surface of mandibular central incisors in complete denture wearers (Table 5).

\begin{tabular}{|c|c|c|c|}
\hline Group & Range & Mean & $\begin{array}{c}\text { Standard } \\
\text { deviation }\end{array}$ \\
\hline Group-1 & $9 \mathrm{~mm}$ to $12 \mathrm{~mm}$ & $10.8 \mathrm{~mm}$ & 0.894 \\
\hline Group-2 & $9 \mathrm{~mm}$ to $13 \mathrm{~mm}$ & $10.47 \mathrm{~mm}$ & 1.639 \\
\hline Group-3 & $9 \mathrm{~mm}$ to $15 \mathrm{~mm}$ & $10.7 \mathrm{~mm}$ & 1.674 \\
\hline
\end{tabular}

Table 1: Range, mean value and standard deviation for variable-1.

\begin{tabular}{|c|c|c|c|}
\hline Group & Range & Mean & $\begin{array}{c}\text { Standard } \\
\text { deviation }\end{array}$ \\
\hline Group-1 & $17 \mathrm{~mm}$ to $20.5 \mathrm{~mm}$ & $18.62 \mathrm{~mm}$ & 1.086 \\
\hline Group-2 & $16.5 \mathrm{~mm}$ to $21 \mathrm{~mm}$ & $17.65 \mathrm{~mm}$ & 1.46 \\
\hline Group-3 & $18 \mathrm{~mm}$ to $26 \mathrm{~mm}$ & $23.47 \mathrm{~mm}$ & 2.7 \\
\hline
\end{tabular}

Table 2: Range, mean value and standard deviation for variable-2. P:0.0001*

\begin{tabular}{|c|c|c|c|}
\hline Group & Range & Mean & $\begin{array}{c}\text { Standard } \\
\text { deviation }\end{array}$ \\
\hline Group-1 & $14 \mathrm{~mm}$ to $16 \mathrm{~mm}$ & $14.85 \mathrm{~mm}$ & 1.052 \\
\hline Group-2 & $13 \mathrm{~mm}$ to $17 \mathrm{~mm}$ & $15.1 \mathrm{~mm}$ & 1.438 \\
\hline Group-3 & $12 \mathrm{~mm}$ to $21 \mathrm{~mm}$ & $16.57 \mathrm{~mm}$ & 2.58 \\
\hline
\end{tabular}

Table 3: Range, mean value and standard deviation for variable-3. 
Citation: Sidana V, Pasricha N, Nanda S, Mann N (2017) A Cephalometric Study of Relationship of Anterior Teeth to Incisive Papilla, Mucolabial Reflections and A-Pogonion Line in Dentulous Subjects and In Complete Denture Wearers. Oral health case Rep 3: 137. doi:10.4172/24718726.1000137

Page 4 of 6

\begin{tabular}{|c|c|c|c|}
\hline Group & Range & Mean & $\begin{array}{c}\text { Standard } \\
\text { deviation }\end{array}$ \\
\hline Group-1 & $2 \mathrm{~mm}$ to $7 \mathrm{~mm}$ & $5.3 \mathrm{~mm}$ & 1.4546 \\
\hline Group-2 & $2 \mathrm{~mm}$ to $8 \mathrm{~mm}$ & $5.775 \mathrm{~mm}$ & 2.27 \\
\hline Group-3 & $4 \mathrm{~mm}$ to $10.5 \mathrm{~mm}$ & $6.025 \mathrm{~mm}$ & 1.908 \\
\hline
\end{tabular}

Table 4: Range, mean value and standard deviation for variable-4

\begin{tabular}{|c|c|c|c|}
\hline Group & Range & Mean & $\begin{array}{c}\text { Standard } \\
\text { deviation }\end{array}$ \\
\hline Group-1 & $2 \mathrm{~mm}$ to $6 \mathrm{~mm}$ & $3.736 \mathrm{~mm}$ & 1.627 \\
\hline Group-2 & $2 \mathrm{~mm}$ to $6 \mathrm{~mm}$ & $3.45 \mathrm{~mm}$ & 1.276 \\
\hline Group-3 & $1 \mathrm{~mm}$ to $5 \mathrm{~mm}$ & $3.45 \mathrm{~mm}$ & 1.503 \\
\hline
\end{tabular}

Table 5: Range, mean value and standard deviation for variable-5.

\begin{tabular}{|c|c|c|c|}
\hline Group & Range & Mean & $\begin{array}{c}\text { Standard } \\
\text { deviation }\end{array}$ \\
\hline Group-1 & $1 \mathrm{~mm}$ to $6.5 \mathrm{~mm}$ & $2.35 \mathrm{~mm}$ & 1.571 \\
\hline Group-2 & $2 \mathrm{~mm}$ to $7 \mathrm{~mm}$ & $2.1 \mathrm{~mm}$ & 1.662 \\
\hline Group-3 & $2 \mathrm{~mm}$ to $2.5 \mathrm{~mm}$ & $1.92 \mathrm{~mm}$ & 1.56 \\
\hline
\end{tabular}

Table 6: Range, mean value and standard deviation for variable-6.

\begin{tabular}{|c|c|c|c|}
\hline Group & Range & Mean & $\begin{array}{c}\text { Standard } \\
\text { deviation }\end{array}$ \\
\hline Group-1 & $0 \mathrm{~mm}$ to $4 \mathrm{~mm}$ & $2.35 \mathrm{~mm}$ & 1.55 \\
\hline Group-2 & $0 \mathrm{~mm}$ to $3 \mathrm{~mm}$ & $2.1 \mathrm{~mm}$ & 1.61 \\
\hline Group-3 & $1 \mathrm{~mm}$ to $3.5 \mathrm{~mm}$ & $1.92 \mathrm{~mm}$ & 1.58 \\
\hline
\end{tabular}

Table 7: Range, mean value and standard deviaton for variable-7.

\begin{tabular}{|c|c|c|}
\hline Groups Compared & Mean Difference & Conclusion \\
\hline Group-3-Group-2 & $5.82 \mathrm{~mm}$ & Significant \\
\hline Group-3-Group-1 & $4.85 \mathrm{~mm}$ & Non-significant \\
\hline Group-1-Group-2 & $0.97 \mathrm{~mm}$ & Non-significant \\
\hline
\end{tabular}

Table 8: Duncan comparison test for variable-2.

\begin{tabular}{|c|c|c|}
\hline Group & Mean Difference & Conclusion \\
\hline Group-3-Group-2 & $1.47 \mathrm{~mm}$ & Significant \\
\hline Group-3-Group-1 & $1.72 \mathrm{~mm}$ & Significant \\
\hline Group1-Group-2 & $0.25 \mathrm{~mm}$ & Non-significant \\
\hline
\end{tabular}

Table 9: Duncan comparison test for variable-3.

Variable-6: The horizontal distance between the maxillary incisor tip and the A-Pog line in dentulous subjects and in complete denture wearers (Table 6).

Variable-7: The horizontal distance between the mandibular incisor tip and the A-Pog line in dentulous subjects and in the complete denture wearers (Table 7).

Further Duncan comparison test for Variable-2 and Variable-3 was done since the $p$ value for variables 2 and 3 were 0.0001 and 0.008 respectively (Tables 8 and 9).

\section{Discussion}

Prosthodontic treatment restores the lost support. Regardless of judgment and technical ability the dentist can place the artificial teeth more correctly if some natural stable landmarks are available to guide.

\section{Incisive papilla}

Incisive papilla is located distal to lingual embrasure between the maxillary central incisors. According to Boucher and others; incisive papilla is a guide to anterior teeth position because it has constant relationship to natural central incisors [6]. Martone stated that for the adequate lip support the labial surface of the teeth should be $8 \mathrm{~mm}$ to $10 \mathrm{~mm}$ in front of incisive papilla [7]. Ellingers in his study measured the distance from the distal margin of incisive papilla to maxillary incisor and he stated that distal margin of papilla is more reliable guide [8]. Hence in the present study the horizontal distance was measured from distal margin of incisive papilla to the labial surface of maxillary incisors in dentulous subjects and in complete denture wearers. The findings of the study indicated that for the dentulous subjects the mean distance obtained in group-1 and group-2 were $10.8 \mathrm{~mm}$ and 10.475 $\mathrm{mm}$ respectively. Minimum distance found was $9 \mathrm{~mm}$ and maximum distance was $13 \mathrm{~mm}$ for both the groups (Table 1). These findings are comparable to those obtained by Ellinger. The measurement recorded by Ellinger varied from $10 \mathrm{~mm}$ to $15 \mathrm{~mm}$.

The distance of the incisive papilla to maxillary central incisor will vary with size of teeth, labiolingual thickness of alveolar process. Further, as stated by Roraff; the distance will vary with arch form also [9].

The study also determined the extent to which artificial teeth are placed labiolingually in complete denture by measuring the distance between the distal margin of incisive papilla and the maxillary central incisors. The mean distance found for this group was $10.7 \mathrm{~mm}$. The minimum distance was $9 \mathrm{~mm}$ and the maximum distance was $15 \mathrm{~mm}$ (Table 1). Values obtained were statistically analyzed there was no significant difference between various groups.

\section{Mucolabial reflections}

In the second part of study the vertical distance between mucolabial reflections and maxillary and mandibular incisor tip and horizontal distance between the mucolabial reflections and the labial surface of maxillary and mandibular incisors were measured in dentulous subjects and in complete denture wearers.

The mean vertical distance between maxillary incisors tip and mucolabial reflection recorded for dentulous subjects in group-1 was $18.62 \mathrm{~mm}$. The minimum distance was $16 \mathrm{~mm}$ and maximum distance was $20 \mathrm{~mm}$ (Table 2).

The mean vertical distance between maxillary incisor tip and mucolabial reflection recorded for dentulous subjects in group-2 was $17.65 \mathrm{~mm}$. The minimum distance was $16.5 \mathrm{~mm}$ and maximum distance was $21 \mathrm{~mm}$. The mean vertical distance recorded for dentulous subjects in group-l was $14.85 \mathrm{~mm}$. The minimum distance was 13 $\mathrm{mm}$ and maximum distance was $16 \mathrm{~mm}$. The mean vertical distance between mandibular incisors tip and mucolabial reflection recorded for dentulous subjects in Group-2 was $15.1 \mathrm{~mm}$. The minimum distance was $13 \mathrm{~mm}$ and maximum distance was $17.5 \mathrm{~mm}$. These findings are comparable to the findings of Ellinger [8]. He obtained a range of $17.3 \mathrm{~mm}$ to $23 \mathrm{~mm}$ for the distance between maxillary incisor tip and mucolabial reflection and range of $13 \mathrm{~mm}$ to $19.6 \mathrm{~mm}$ for mandibular incisor tip to mucolabial reflections (Table 2).

The vertical distance between the denture border and maxillary incisor tip and denture border and mandibular incisor tip was measured in group- 3 subjects. The mean distance was $23.47 \mathrm{~mm}$ and $16.57 \mathrm{~mm}$ respectively. The minimum distance from denture border to mandibular incisor was $18 \mathrm{~mm}$ and maximum distance was $26 \mathrm{~mm}$. The minimum distance from denture border to mandibular incisor was $12 \mathrm{~mm}$ and maximum distance was $21 \mathrm{~mm}$ (Table 3).

The values recorded for complete denture were higher than the values for dentulous subjects. These increased vertical distances in complete denture wearers can be attributed to the fact that for the sake 
Citation: Sidana V, Pasricha N, Nanda S, Mann N (2017) A Cephalometric Study of Relationship of Anterior Teeth to Incisive Papilla, Mucolabial Reflections and A-Pogonion Line in Dentulous Subjects and In Complete Denture Wearers. Oral health case Rep 3: 137. doi:10.4172/24718726.1000137

Page 5 of 6

of peripheral sealing the dentures are usually carried to the functional depth of sulcus which may bring about slight displacement of the soft tissues by Devan in 1960 [10]. Further it can also be due to fact that in complete dentures the upper and lower incisor are set according to visibility this is in accordance with Watson and Bhatia who stated that incisors are set at lower level from maxillary plane than that found in natural dentition matching longer edentulous upper lip [11]. Further the size of maxillary edentulous ridge too influences the vertical position of upper incisor teeth and these tend to be set at lower level than maxillary plane in well-developed maxillary ridge cases. In this part of study, the mean horizontal distance between mucolabial reflections and labial surface of maxillary and mandibular incisors were recorded. The mean horizontal distance between the mucolabial reflection and labial surface of maxillary incisor for dentulous subjects in group-l was $5.3 \mathrm{~mm}$. The minimum distance was $2 \mathrm{~mm}$ and maximum distance was $7 \mathrm{~mm}$ (Table 4). The mean horizontal distance between the mucolabial reflection and labial surface of maxillary incisor for dentulous subjects in group- 2 was $5.7 \mathrm{~mm}$. The minimum distance was $2 \mathrm{~mm}$ and maximum distance was $8 \mathrm{~mm}$ (Table 4).

The mean horizontal distance between mucolabial reflection and labial surface of mandibular incisor for dentulous subjects in group-1 was $3.7 \mathrm{~mm}$. The minimum distance was $2 \mathrm{~mm}$ and maximum distance was $6 \mathrm{~mm}$ (Table 5). The mean horizontal distance between mucolabial reflection and labial surface of mandibular incisor for dentulous subjects in group- 2 was $3.4 \mathrm{~mm}$. The minimum distance was $2 \mathrm{~mm}$ and maximum distance was $6 \mathrm{~mm}$ (Table 5). These findings favor comparably to the findings of Ellinger [8]. He obtained a range of $1.2 \mathrm{~mm}$ to $8.5 \mathrm{~mm}$ for the horizontal distance between mucolabial reflection and labial surface of maxillary incisor and range of $0.8 \mathrm{~mm}$ to $7.4 \mathrm{~mm}$ for horizontal distance between the mucolabial reflection and labial surface of mandibular incisor. Further, the horizontal distances between the denture borders and the labial surfaces of maxillary and mandibular incisor were measured in group-3, subjects. The mean distance from denture border to labial surface of maxillary incisor was $6.025 \mathrm{~mm}$. The minimum distance was $4 \mathrm{~mm}$ and maximum distance was $10.5 \mathrm{~mm}$. The mean distance from denture border to labial surface of mandibular incisor was $3.45 \mathrm{~mm}$. The minimum distance was $1 \mathrm{~mm}$ and maximum distance was $5 \mathrm{~mm}$ (Table 5). Values obtained were statistically analyzed and there was no significant difference between the various groups.

\section{A-Pogonion}

Cephalometrics norms have been proposed relating anterior teeth to various reference lines and planes. A-Pogonion has been identified as a line which is intimately related to the profile and stability of dentition. In this part of study an attempt was made to determine, the horizontal relationship between maxillary incisor and A-pog line and mandibular incisor and the A-pog line in dentulous subjects and complete denture wearers. Ricketts [2] recorded the mean horizontal distance between maxillary incisor and A-pog line to be $5.7 \mathrm{~mm}$ and for the mandibular incisor and A-pog line the horizontal distance was $1 \mathrm{~mm}$. In the present study, the mean values obtained for the horizontal distance between maxillary incisor tip and A-pog line was $5.37 \mathrm{~mm}$ for group-I. The minimum distance was $1 \mathrm{~mm}$ and the maximum distance was $6 \mathrm{~mm}$. The mean horizontal distance recorded between maxillary incisor tip and A-pog line was $5 \mathrm{~mm}$ for group-2. The minimum distance obtained was $2 \mathrm{~mm}$ and the maximum distance obtained was $7 \mathrm{~mm}$. (Table 6)

The mean horizontal distance between mandibular incisor tip and A-pog line was $2.35 \mathrm{~mm}$ for group-l. The minimum distance was 2 $\mathrm{mm}$ and the maximum distance was $7 \mathrm{~mm}$. The mean value obtained for horizontal distance between mandibular incisor and A-pog line was $2.1 \mathrm{~mm}$ for group-2. The minimum distance was $0 \mathrm{~mm}$ and the maximum distance was $3 \mathrm{~mm}$ (Table 7). The above findings compare favorably with the findings obtained by Ricketts. Further, an attempt was made to determine the extent to which artificial teeth arranged for complete dentures approximated the mean values as obtained from adult dentulous subject. The mean value for distance between maxillary incisor and A-pog line in group-3 subjects was $4.29 \mathrm{~mm}$ and the mean distance between mandibular incisor and A-Pog line in group-3 subjects was $1.29 \mathrm{~mm}$ (Table 7). The values obtained were statistically analyzed and there was no significant difference between various groups.

From the evaluation of above discussion, it is said that within dentulous subjects there is no significant difference in horizontal or vertical relationship of anterior teeth with various landmarks in respective age groups. In case of complete dentures which were constructed to esthetic and phonetics sense of dentist, there is not much variation in labiolingual position of anterior teeth. However, there was slight increase in vertical measurement, which may be attributed to the fact that for the sake of peripheral sealing, the denture bases are usually carried to the functional depth of sulcus which may bring about slight displacement soft tissues. Further, with aging there is reduced muscle tonicity and decreased lip activity, which might have not been taken into consideration while establishing maxillary occlusal plane. The maxillary occlusal plane and teeth are arranged according to the normal visibility norms, which might have resulted in increased vertical distance.

In this study, the subjects were selected randomly without considering the shape of the arch and shape of the face for both dentulous subjects and complete denture wearers. Further, the horizontal distance between the labial surface of incisors and incisive papilla may vary with arch shape as stated by Roraff $[9,11]$. The labial surface of the central incisor was considered as the maximum convexity, which may vary with inclination of the teeth.

\section{Summary and Conclusion}

The restoration of natural and pleasing lip support is one of the prime requisites of an esthetic denture. According to Frush and Fisher pleasing lip support for edentulous patients is achieved by correct placement of anterior teeth and their matrix, with burden being placed on central incisors [12]. Pound stated that to achieve a natural look, nature should be imitated by placing artificial teeth in the same position as occupied by natural teeth. In this study efforts were made to determine the relationship of maxillary incisors to the distal margin of incisive papilla in dentulous subjects and in complete denture wearers. Further the relationship of mucolabial reflections to maxillary and mandibular incisors and the relationship of A-Pog line to maxillary and mandibular incisors in both dentulous subjects and in complete dentures wearers were also evaluated. Based on the results the following conclusions were drawn-

1. There was no significant difference in horizontal distance between the distal margin of incisive papilla and labial surface of maxillary incisors in dentulous subjects belonging to different age groups and in complete denture wearers, which were constructed to esthetics and phonetic sense of dentist.

2. The vertical distance between the mucolabial reflection and tips of maxillary and mandibular incisors were recorded in both dentulous subjects and in complete denture wearers there 
Citation: Sidana V, Pasricha N, Nanda S, Mann N (2017) A Cephalometric Study of Relationship of Anterior Teeth to Incisive Papilla, Mucolabial Reflections and A-Pogonion Line in Dentulous Subjects and In Complete Denture Wearers. Oral health case Rep 3: 137. doi:10.4172/24718726.1000137

Page 6 of 6

was no statistically significant difference in dentulous subjects of different age groups. However, in complete denture wearers there was an increase in vertical distance between denture border and maxillary and mandibular incisor tips.

3. There was no significant difference in horizontal distance between mucolabial reflections and labial surface of maxillary and mandibular incisors in dentulous subjects belonging to different age groups and in complete denture wearers, which were constructed to esthetic and phonetic sense of dentist.

4. There was no significant difference in horizontal distance between A-Pogonion line and tips of maxillary and mandibular incisors in dentulous subjects belonging to different age groups and in complete denture wearers, which were constructed to esthetic and phonetic sense of dentist.

The results of this study indicate that within dentulous subjects there is no significant difference in the horizontal or vertical relationship of anterior teeth with various landmarks such as incisive papilla, mucolabial reflections and A-Pog line, irrespective of age group. In complete denture wearers, which were constructed to esthetic and phonetic sense of dentist, there is not much variation in labiolingual position of anterior teeth, as compared to the natural teeth, however there was slight increase in vertical measurement from the denture borders to the tips of maxillary and mandibular incisors. There is no universal fact that the measurements outlines are static. The intent is not that of providing range of acceptability or conversely unacceptability. However certain findings may be used as guidelines in the initial placement of the anterior teeth and shaping of denture border.

\section{References}

1. Grave $A M H$, Becker JP (1987) Evaluation of incisive papilla as a guide to anterior teeth position. J Prosthet Dent 57: 712-714.

2. Rickets RM (1957) Planning treatment on the basis of the facial pattern and an estimate of its growth. Angle Orthod 27: 14-37.

3. Schudyl F (1964) Can't of occlusal plane and axial inclination of teeth. Angle Orthod 23: 69-82.

4. Ciftci Y, Kokadereli I, Canay S, Senyilmaz P (2005) Cephalometric evaluation of maxillomandibular relationships in patients wearing complete dentures: A pilot study Angle. Orthod 75: 821-825.

5. Antonija P, Peter B, Vesna C, Ivan K (2013) Association of cephalometric changes after five years of complete dentures wearing and oral health related quality of life. Acta Odontol Scand 71: 449-456.

6. Bolender Z. Boucher prosthodontic treatment for edentulous patients. Mosby Pub Ltd 1998, USA. pp. 240-241.

7. Martone AL (1962) Anatomy of facial expression and its prosthodontic significance. J Prosthet Dent 12: 1020-1042.

8. Ellinger CW (1968) Radiographic study of oral structures and their relation to anterior tooth position. J Prosth Dent 19: 36-45

9. Roraff AR (1977) Arranging artificial teeth according to anatomical landmarks J Prosth Dent 38: 120-130.

10. DeVan MM (1957) The appearance phase of denture construction. Dent Clin North Am 2: 255-268.

11. Watson RM, Bhatia SN (1989) Tooth positions in the natural and complete artificial dentitions with special reference to the incisor teeth. An interactive online computer analvsis. J Oral rehabilitation. 16: 139-153.

12. Frush JP, Fisher RD (1959) Dentogenics: Its practical application. J Prosthet Dent 9: 914-921. 